\title{
Muscle Activation and Estimated Relative Joint Force During Running with Weight Support on a Lower-Body Positive-Pressure Treadmill
}

\author{
Bente R. Jensen, Line Hovgaard-Hansen, and Katrine L. Cappelen \\ University of Copenhagen
}

\begin{abstract}
Running on a lower-body positive-pressure (LBPP) treadmill allows effects of weight support on leg muscle activation to be assessed systematically, and has the potential to facilitate rehabilitation and prevent overloading. The aim was to study the effect of running with weight support on leg muscle activation and to estimate relative knee and ankle joint forces. Runners performed 6-min running sessions at $2.22 \mathrm{~m} / \mathrm{s}$ and $3.33 \mathrm{~m} / \mathrm{s}$, at $100 \%, 80 \%, 60 \%, 40 \%$, and $20 \%$ body weight (BW). Surface electromyography, ground reaction force, and running characteristics were measured. Relative knee and ankle joint forces were estimated. Leg muscles responded differently to unweighting during running, reflecting different relative contribution to propulsion and antigravity forces. At $20 \% \mathrm{BW}$, knee extensor $\mathrm{EMG}_{\text {peak }}$ decreased to $22 \%$ at $2.22 \mathrm{~m} / \mathrm{s}$ and $28 \%$ at $3.33 \mathrm{~m} / \mathrm{s}$ of $100 \% \mathrm{BW}$ values. Plantar flexors decreased to $52 \%$ and $58 \%$ at $20 \%$ BW, while activity of biceps femoris muscle remained unchanged. Unweighting with LBPP reduced estimated joint force significantly although less than proportional to the degree of weight support (ankle). It was concluded that leg muscle activation adapted to the new biomechanical environment, and the effect of unweighting on estimated knee force was more pronounced than on ankle force.
\end{abstract}

Keywords: rehabilitation, body weight support, EMG, estimated joint load, running

Early mobilization after injury and surgery on the lower extremities is essential to reduce adverse effects of immobilization and to facilitate rehabilitation. Walking or running with weight support on a lower-body positive-pressure (LBPP) treadmill is a new training and rehabilitation modality. ${ }^{1,2} \mathrm{~A}$ recent study indicated strong correlation between tibiofemoral force and treadmill ground reaction force in a small group of elderly patients during slow walking. ${ }^{3}$ Another study showed that runners can reduce peak vertical ground reaction forces while maintaining the aerobic stimulus when running on a LBPP treadmill. ${ }^{4}$ Even training at high speeds and high aerobic stimuli with the benefit of low vertical ground reaction force and near-normal movement pattern can be performed on the LBPP treadmill. ${ }^{5}$ Furthermore, no adverse impact on systemic and head cardiovascular parameters has been found. ${ }^{6}$ However, the effect of different levels of LBPP weight support during running on neuromuscular adaptations and their possible associations to joint forces have not been studied systematically.

During level running, leg muscles support body weight (BW) against gravity and accelerate/decelerate the body mass in a forward direction. BW, as measured in Newton, is directly related to gravity, while body mass $(\mathrm{kg})$ is independent of gravity. Therefore, by unweighting in a LBPP chamber, it is possible to create a new

Bente R. Jensen, Line Hovgaard-Hansen, and Katrine L. Cappelen are with the Biomechanics and Motor Control Laboratory, Integrative Physiology, Department of Nutrition, Exercise and Sport, University of Copenhagen, Denmark. Address author correspondence to Bente R. Jensen at brjensen@ nexs.ku.dk. biomechanical environment where the vertical forces are reduced while forces associated with horizontal acceleration/deceleration of the body remain unchanged. This allows systematic study of individual leg muscle contribution to body support against gravity and to propulsion. It seems reasonable to expect a muscle-specific effect of gradual weight support on muscle activation during running in a LBPP chamber. However, knowledge is sparse regarding the muscle-specific effect of increasing weight support on muscle activation levels and temporal activation patterns during running.

Lower extremity joint compression forces during running have been assessed using electromyography (EMG) based models, inverse dynamics, and model simulations assuming a priori force distributions. Values between 8 to 14 times BW for knee and ankle joint compression forces during running have been reported in the literature. ${ }^{7-10}$ The relative large variations between studies are attributed to the different models and assumptions used in the studies. Ground reaction forces as well as muscle forces contribute to joint forces, with muscle forces being the major contributor to mechanical joint load. ${ }^{9}$ It has been estimated that muscle forces amount to 7 to 8 times BW, while ground reaction force contributes an additional 2 to 3 times BW during running. ${ }^{10}$ We hypothesized that vertical ground reaction force is reduced proportionally to increasing weight support, while muscle activation is reduced less than proportional to the degree of weight support, as forces related to horizontal propulsion remain unchanged despite changes in weight support. Furthermore, we hypothesized that estimated joint force is reduced markedly but less than proportional to the degree of weight support. The main aim was to study the effect of weight support with LBPP on leg muscle activation, ground reaction force, and estimated relative knee and ankle joint forces during running. In addition, effects of weight support on running characteristics were assessed. 


\section{Methods}

\section{Participants}

Eight healthy, experienced male runners with a mean age of 27.6 $( \pm 2.4)$ years, body mass $80.1( \pm 6.8) \mathrm{kg}$, and body height $1.84( \pm$ $0.07) \mathrm{m}$ participated. Resting blood pressure and heart rate (sitting position) were 140/77 ( \pm 9.4/ \pm 7.0) $\mathrm{mmHg}$ and $63( \pm 8) \mathrm{bpm}$, respectively. All subjects gave written consent to participate in the study, which was approved by the local ethics committee.

\section{Protocol}

The subjects performed 2 running sessions at $2.22 \mathrm{~m} / \mathrm{s}$ and $3.33 \mathrm{~m} / \mathrm{s}$ on a force treadmill with a LBPP chamber (Alter-G P200, Alter G, California, USA), which allowed BW to be reduced gradually from $100 \%$ BW to $20 \%$ BW. The LBPP treadmill system was constructed as a treadmill (Woodway, USA) surrounded by a pressure chamber. The subjects wore a special type of shorts and were zipped at the waist into a pressurized airtight enclosure that is suspended over the surface of the treadmill. By controlling the pressure in the enclosure, it is possible to support BW of an individual to $20 \%$ of normal $\mathrm{BW}$ in $1 \%$ increments. The treadmill is mounted with 4 force transducers (aluminum load cell, $1000 \mathrm{LBF}, 2.0 \mathrm{mV} / \mathrm{V}$ ), which allowed vertical ground reaction force during ambulation to be monitored. The pressure/ground reaction force relation in the LBPP chamber was calibrated during still standing for each participant individually. The system allows unrestricted mobility and natural movement pattern during ambulation. The 2 running sessions were performed in random order and at least 20 minutes of rest was allowed between sessions to avoid fatigue. Each session consisted of 6-minute running trials at $100 \% \mathrm{BW}, 80 \% \mathrm{BW}, 60 \%$ BW, $40 \%$ BW, and $20 \%$ BW. At all levels of BW support, subjects were instructed to run as normal as possible with the body centered in the pressure chamber.

\section{Measurements and Data Analysis}

Bipolar surface EMG (8-channel, Logger Technology, Sweden) was recorded from the vastus lateralis (VL), vastus medialis (VM), biceps femoris (BF), lateral gastrocnemius (GAS), and lateral soleus (SOL) muscles using $\mathrm{Ag} / \mathrm{AgCl}$ electrodes (Neuroline 720, Ambu, Denmark) that were placed with an interelectrode center-to-center distance of $2 \mathrm{~cm}$. The skin was carefully cleaned with alcohol, shaved, and rubbed to obtain an interelectrode resistance below $10 \mathrm{~K} \Omega$. EMG was recorded during running and during maximum contractions performed before the running sessions. Four types of maximum contractions were performed. Each type was repeated 3 times. Maximum EMG $\left(\mathrm{EMG}_{\max }\right)$ for the $\mathrm{VL}$ and $\mathrm{VM}$ muscles was obtained during isometric knee extensions performed in sitting position with a knee angle of $100^{\circ}$ degrees. Maximum isometric knee flexions were performed in the same position to obtain maximum EMG from the BF muscle. Maximum EMG for the SOL and GAS muscles was recorded during maximum isometric ankle plantar flexions measured with the subjects in a sitting position $\left(90^{\circ} \mathrm{knee}\right.$ angle, $90^{\circ}$ ankle angle) with a vertical lower leg. The leg was fixed to the floor with a strap across the knee. Finally, maximum plantar flexions were performed while the subjects were standing on $1 \mathrm{leg}$, while forces were exerted on the shoulders. EMG was recorded using a sampling frequency of $1000 \mathrm{~Hz}$ (DT BNC Box USB 9800 Series, 16 bit, Data translation Inc., USA). Root mean square (RMS) amplitudes of the EMG were calculated in 100-millisecond segments. For the maximum contractions, moving averages of 10 consecutive RMS values ( $1 \mathrm{~s})$ were calculated. The largest 1 -second value for each muscle was determined as maximum $\mathrm{EMG}\left(\mathrm{EMG}_{\max }\right)$ and used to normalize EMG measured during running $\left(\% \mathrm{EMG}_{\max }\right)$ to allow comparisons of relative EMG between muscles. Average muscle activity $\left(\mathrm{EMG}_{\text {mean }}\right)$ and peak muscle activity $\left(\mathrm{EMG}_{\text {peak }}\right)$ (the $90 \%$ percentile, ie, the level exceeded $10 \%$ of the time) during running were calculated for each trial in minutes 4 to $6 . \mathrm{EMG}_{\text {peak }}$ is expected to reflect peak force in the stance phase.

Treadmill force transducers were calibrated using 8 loads between $0 \mathrm{~kg}$ and $71 \mathrm{~kg}$. The static calibration showed a linear relation between external load and transducer output $\left(R^{2}=.99\right)$. The dynamic damping characteristics based on single impacts between $900 \mathrm{~N}$ and $2400 \mathrm{~N}$ showed a resonant (fundamental) frequency of 16.2 $\mathrm{Hz}$ and an impact amplitude reduction of 94\% at T0. Thus, the transducers were high precision load cells with low resonance. The summed force signal from the 4 load cells in the treadmill was recorded during the running sessions with a frequency of 1000 Hz (DT BNC Box USB 9800 Series, 16 bit, Data translation Inc., USA). Force data were used to calculate peak ground reaction forces $\left(\mathrm{GRF}_{\text {peak }}\right)$ as the $90 \%$ force (ie, the level of force exceeded $10 \%$ of the time) and mean ground reaction forces $\left(\mathrm{GRF}_{\text {mean }}\right)$. Force calculations are based on minutes 4 to 6 during the trials. Furthermore, measures of running kinematics (cadence and relative stance duration) were calculated based on GRF data. The reported data are average values for the fifth minute of the trials.

\section{Model Estimation of Relative Joint Force}

Relative knee and ankle peak joint force reductions at weightsupported conditions were estimated based on $\mathrm{GRF}_{\text {peak }}$ and $\mathrm{EMG}_{\text {peak }}$ values and assuming $20 \%$ contribution from ground reaction force and $80 \%$ contribution of muscle activation to joint forces: ${ }^{10}$ relative peak joint force $=\left(\mathrm{k}_{1}\left(\mathrm{rel}-\mathrm{GRF}_{\text {peak }}\right)+\mathrm{k}_{2}\left(\mathrm{rel}-\mathrm{EMG}_{\text {peak }}\right)\right) \times$ $100 \% \mathrm{BW}$, where $\mathrm{k}_{1}=0.2, \mathrm{k}_{2}=0.8$, and rel $-\mathrm{GRF}_{\text {peak }}=\mathrm{GRF}_{\text {peak }}$ at weight-supported condition divided by $\mathrm{GRF}_{\text {peak }}$ at $100 \% \mathrm{BW}$. For the knee: rel $-\mathrm{EMG}_{\text {peak-k }}=\left(\mathrm{EMG}_{\text {peak }}\right.$ for $\mathrm{VL}+\mathrm{EMG}_{\text {peak }}$ for $\left.\mathrm{VM}\right)$ / 2 at weight-supported conditions divided by $\left(\mathrm{EMG}_{\text {peak }}\right.$ for $\mathrm{VL}+$ $\mathrm{EMG}_{\text {peak }}$ for VM) / 2 at $100 \% \mathrm{BW}$.

For the ankle: rel $-\mathrm{EMG}_{\text {peak-a }}=\left(\mathrm{EMG}_{\text {peak }}\right.$ for $\mathrm{GAS}+\mathrm{EMG}_{\text {peak }}$ for SOL) / 2 at weight supported conditions divided by $\left(\mathrm{EMG}_{\text {peak }}\right.$ for $\mathrm{GAS}+\mathrm{EMG}_{\mathrm{peak}}$ for SOL) / 2 at $100 \% \mathrm{BW}$.

\section{Statistical Analysis}

Statistical analyses were performed using Minitab (MTB version 13; Minitab, USA). A general linear model with BW and velocity as fixed factors was used to identify the effect of weight support and velocity on $\mathrm{EMG}_{\text {mean }}, \mathrm{EMG}_{\text {peak, }}, \mathrm{GRF}_{\text {mean, }} \mathrm{GRF}_{\text {peak, }}$ step frequency, and relative duration of the stance phase. No interactions were found between BW and velocity. Estimated knee joint load and estimated ankle joint load were compared by paired $T$-test. The threshold for statistical significance was set at $P=.05$.

\section{Results}

The time courses of the muscle activation patterns at different levels of weight support were qualitatively similar, although leg muscles responded differently regarding amplitude adaptations to gradual weight support. Muscle activation pattern of the leg muscles as well as ground reaction force for a typical subject are shown in Figure 1. 


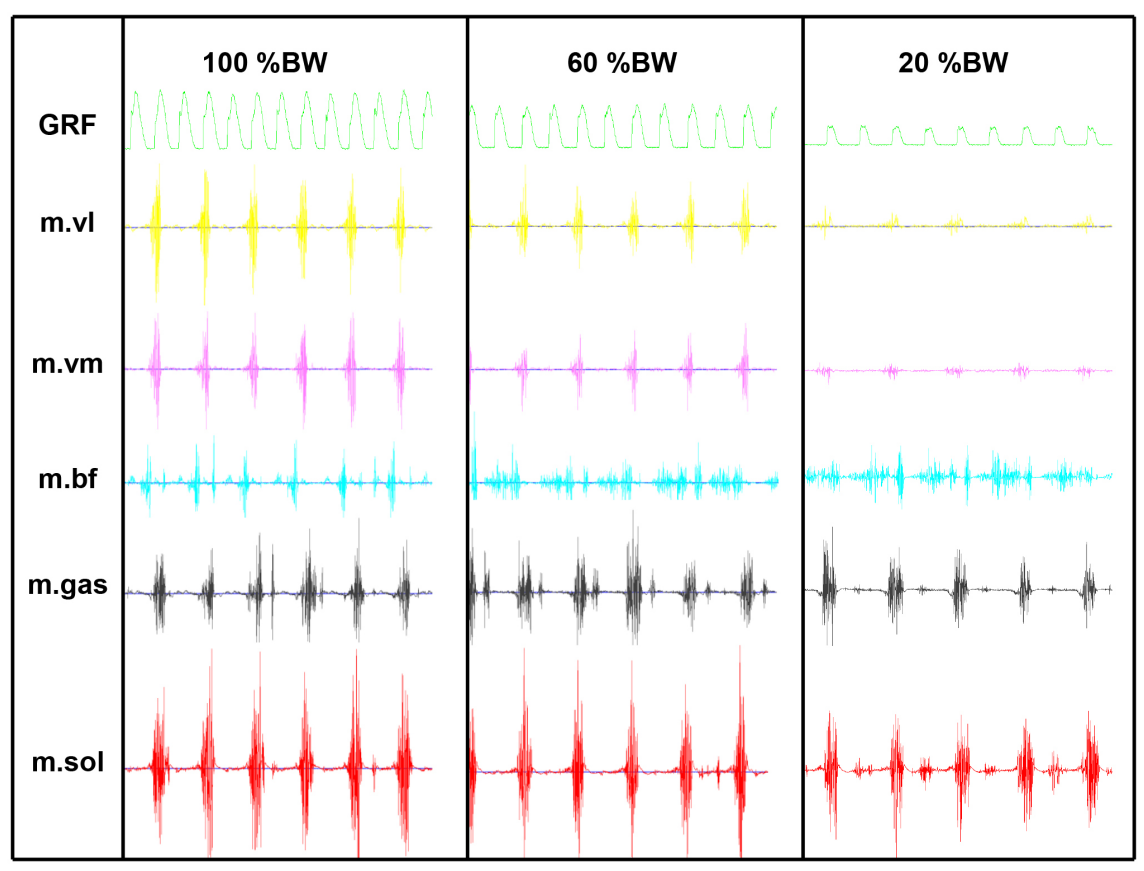

Figure 1 - An example of vertical ground reaction force (GRF) and raw electromyography (EMG) from the vastus lateralis (m.vl), vastus medialis (m.vm), biceps femoris (m.bf), gastrocnemius (m.gas), and the soleus (m.sol) muscles while running at 100\% body weight (BW), 60\% BW, and 20\% $\mathrm{BW}(\mathrm{n}=1)$. A major response to reduced BW was seen for the knee extensor muscles. A less marked response was seen for the plantar flexor muscles.

$\mathrm{EMG}_{\text {mean }}(\mathrm{VL}, \mathrm{VM}, \mathrm{SOL}, \mathrm{GAS})$ decreased with increasing weight support $(P<.001)$ (Figure $2 \mathrm{~A}, 2 \mathrm{~B})$. Increasing weight support from $100 \% \mathrm{BW}$ to $20 \% \mathrm{BW}$ decreased $\mathrm{EMG}_{\text {mean }}$ to $24.8 \%$ (VL) and $23.3 \%(\mathrm{VM})$ of the values measured at $100 \% \mathrm{BW}$ at $2.22 \mathrm{~m} / \mathrm{s}$, and to $36.1 \%(\mathrm{VL})$ and $28.4 \%(\mathrm{VM})$ at $3.33 \mathrm{~m} / \mathrm{s}$. The corresponding values for the GAS and SOL muscles were $49.9 \%$ and $46.5 \%$ of $100 \% \mathrm{BW}$ values at $2.22 \mathrm{~m} / \mathrm{s}$, and $58.8 \%$ and $57.7 \%$ at $3.33 \mathrm{~m} / \mathrm{s}$. $\mathrm{EMG}_{\text {mean }}$ of the BF muscle remained unchanged $(P=.959)$ (overall average $9.3 \% \mathrm{EMG}_{\max }$ at $2.22 \mathrm{~m} / \mathrm{s}$ and $10.8 \% \mathrm{EMG}_{\max }$ at $3.33 \mathrm{~m} / \mathrm{s}$ ) when BW was increasingly supported.

$\mathrm{EMG}_{\text {peak }}(\mathrm{VL}, \mathrm{VM}, \mathrm{SOL}, \mathrm{GAS})$ decreased with increasing BW support $(P<.001)$ (Figure 2C, 2D). Thus, unweighting from $100 \%$ BW to $20 \% \mathrm{BW}$ at $2.22 \mathrm{~m} / \mathrm{s}$ decreased $\mathrm{EMG}_{\text {peak }}$ to $23.2 \%$ (VL) and $19.8 \%(\mathrm{VM})$ of the initial values measured at $100 \% \mathrm{BW}$ and to $29.7 \%$ (VL) and $26.2 \%(\mathrm{VM})$ at $3.33 \mathrm{~m} / \mathrm{s}$. For the GAS and the SOL muscles, the corresponding values were $53.8 \%$ and $50.6 \%$ of $100 \% \mathrm{BW}$ values at $2.22 \mathrm{~m} / \mathrm{s}$, and $58.1 \%$ and $58.6 \%$ at $3.33 \mathrm{~m} / \mathrm{s}$. $\mathrm{EMG}_{\text {peak }}$ of the BF muscle remained unchanged $(P=.754)$ (overall mean $19.3 \% \mathrm{EMG}_{\max }$ at $2.22 \mathrm{~m} / \mathrm{s}$ and $23.5 \% \mathrm{EMG}_{\max }$ at $3.33 \mathrm{~m} / \mathrm{s}$ ) despite reduced BW. Knee extensor $\mathrm{EMG}_{\text {peak }}$ (mean of VL and VM muscles) increased by $5.0 \%$ from $2.22 \mathrm{~m} / \mathrm{s}$ to $3.33 \mathrm{~m} / \mathrm{s}$, and ankle plantar flexor $\mathrm{EMG}_{\text {peak }}$ (mean of SOL and GAS) increased by $9.5 \%$ from $2.22 \mathrm{~m} / \mathrm{s}$ to $3.33 \mathrm{~m} / \mathrm{s}$ across all BWs.

$\mathrm{GRF}_{\text {mean }}$ decreased from $98 \% \mathrm{BW}$ to $20 \% \mathrm{BW}$ at $2.22 \mathrm{~m} / \mathrm{s}$, and from to $99 \% \mathrm{BW}$ to $23 \% \mathrm{BW}$ at $3.33 \mathrm{~m} / \mathrm{s}$ when unweighting from $100 \% \mathrm{BW}$ to $20 \% \mathrm{BW}(P<.001) . \mathrm{GRF}_{\text {peak }}$ decreased from $176 \% \mathrm{BW}$ to $55 \% \mathrm{BW}$ at $2.22 \mathrm{~m} / \mathrm{s}$ and from $191 \% \mathrm{BW}$ to $68 \%$ $\mathrm{BW}$ at $3.33 \mathrm{~m} / \mathrm{s}$ when unweighting from $100 \% \mathrm{BW}$ to $20 \% \mathrm{BW}$ $(P<.001)$ (Figure 3$)$.

The effect of increasing BW support from $100 \%$ BW to $20 \%$ $\mathrm{BW}$ on peak joint force reduction was more pronounced for the knee than for the ankle $(P=.007$ at $2.22 \mathrm{~m} / \mathrm{s}$ and $P=.005$ at $3.3 \mathrm{~m} / \mathrm{s})$.
Thus, the estimated knee joint force at $20 \%$ BW corresponded to $23.8 \%$ (at $2.22 \mathrm{~m} / \mathrm{s}$ ) and $28.8 \%$ (at $3.33 \mathrm{~m} / \mathrm{s}$ ) of the initial values, while the estimated ankle joint force at $20 \% \mathrm{BW}$ corresponded to $41.6 \%$ (at $2.22 \mathrm{~m} / \mathrm{s}$ ) and $52.8 \%$ (at $3.33 \mathrm{~m} / \mathrm{s}$ ) of the initial values at $100 \%$ BW (Figure 4).

In addition, step frequency at $2.22 \mathrm{~m} / \mathrm{s}$ declined gradually from $163 \mathrm{steps} / \mathrm{min}$ at $100 \% \mathrm{BW}$ to $126 \mathrm{steps} / \mathrm{min}$ at $20 \% \mathrm{BW}$. The corresponding values at $3.33 \mathrm{~m} / \mathrm{s}$ were $168 \mathrm{steps} / \mathrm{min}$ to $135 \mathrm{steps} / \mathrm{min}$ $(P<.001)$. The relative duration of the stance phase decreased from $74 \%$ of the running cycle to $43 \%$ of the running cycle at $2.22 \mathrm{~m} / \mathrm{s}$, and from $62 \%$ to $38 \%$ of the running cycle at $3.33 \mathrm{~m} / \mathrm{s}(P<.001)$. Furthermore, increasing the running velocity from $2.22 \mathrm{~m} / \mathrm{s}$ to 3.33 $\mathrm{m} / \mathrm{s}$ increased cadence $(P=.005)$ and decreased the relative duration of the stance phase at all levels of BW $(P<.001)$.

\section{Discussion}

An integrated experimental approach was used to estimate neuromuscular and biomechanical effects of unweighting in a LBPP chamber. Running on the LBPP treadmill allows the biomechanical environment to be changed gradually in a well-controlled manner, and the results showed that participants adapted their muscle activation accordingly. The effect of unweighting on muscle activation was more pronounced for the knee extensor muscles than for the plantar flexor muscles. Hamstring activity (BF) remained unchanged. Unweighting reduced $\mathrm{GRF}_{\text {peak }}$ markedly. Model estimation of the effect of unweighting on peak joint force reduction, including contributions from external and internal sources, was more pronounced for the knee than for the ankle joint. Our data on running characteristic confirmed previous data.

Knee extensor and plantar flexor muscle activation decreased gradually when BW was increasingly supported, reflecting that 
$2 \mathrm{~A}$

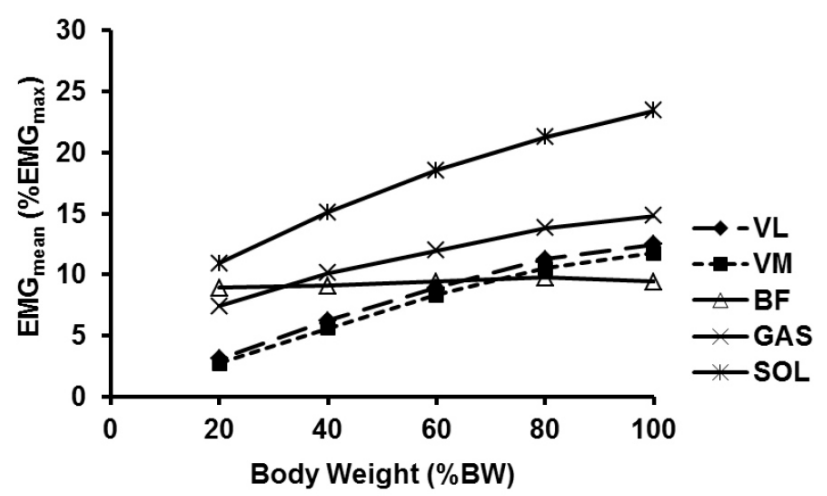

2C

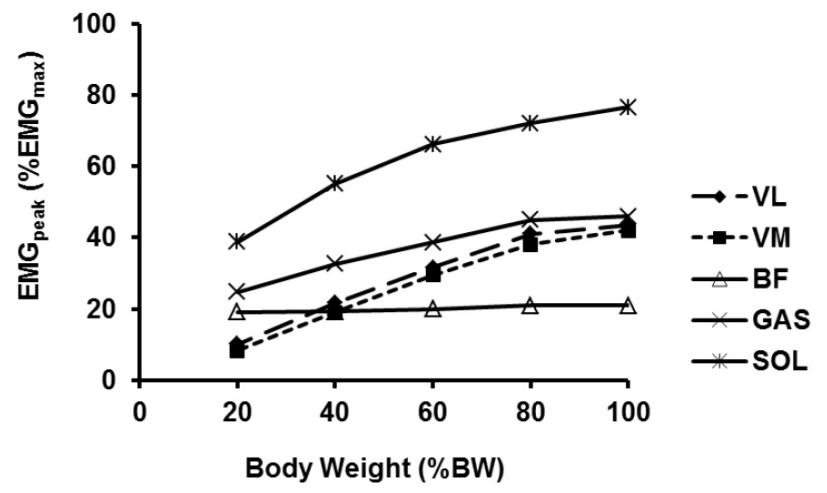

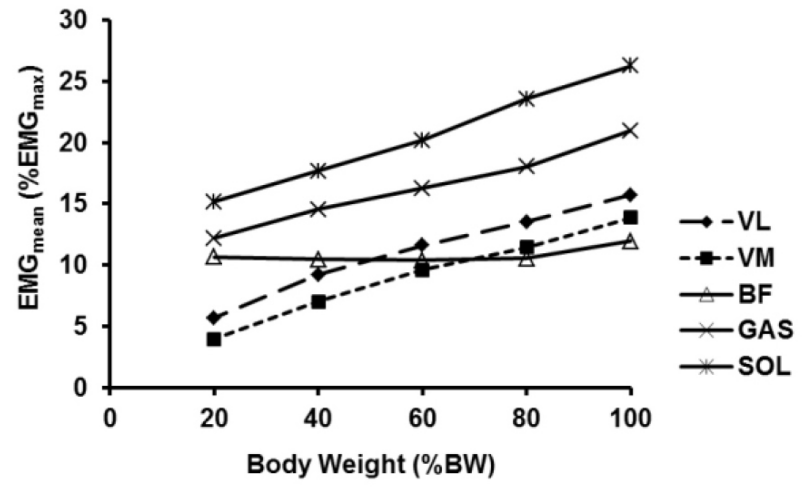

2D

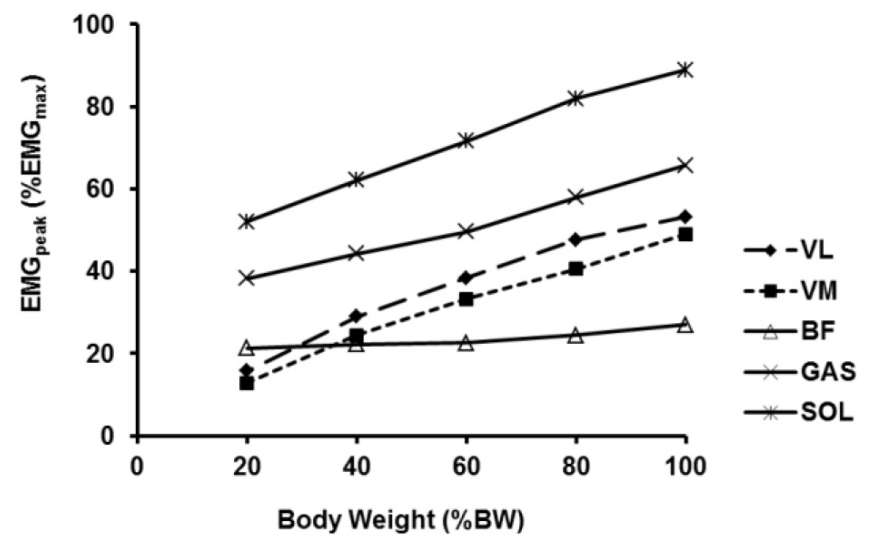

Figure 2 - Electromyography (EMG) from the vastus lateralis (VL), vastus medialis (VM), biceps femoris (BF), gastrocnemius (GAS), and the soleus (SOL) muscles. (A) $\mathrm{EMG}_{\text {mean }}$ at $2.22 \mathrm{~m} / \mathrm{s}$, (B) $\mathrm{EMG}_{\text {mean }}$ at $3.33 \mathrm{~m} / \mathrm{s},(\mathrm{C}) \mathrm{EMG}_{\text {peak }}$ at $2.22 \mathrm{~m} / \mathrm{s},(\mathrm{D}) \mathrm{EMG}_{\text {peak }}$ at $3.33 \mathrm{~m} / \mathrm{s}$. (n = 8).

activation of both muscle groups is dependent on the vertical forces acting on the participant during running. The relative decrease in muscle activity with increasing weight support was largely similar for the 2 knee extensor muscles. Likewise, the reduction in muscle activation was similar for the 2 plantar flexor muscles. However, the 2 muscle groups responded differently to BW reduction. Thus, the relative activation reduction of GAS and SOL was much less pronounced than the reduction of VL and VM activation, indicating different functions of the 2 muscle groups during running. The relative reduction of VL and VM activation corresponded largely to $\mathrm{BW}$ reduction, indicating that the main function of the knee extensor muscles are to resist gravity during running. In contrast, SOL and GAS activities were reduced much less than BW reduction. These data clearly show the dual function of the plantar flexor muscles as important contributors to propulsion and weight support against gravity. In contrast, muscle activation of the BF muscle remained unchanged despite increasing $\mathrm{BW}$ support as BF was mainly active during the leg swing phase, breaking the hip torque and as a stabilizer in the stance phase. Thus, using LBPP to manipulate the biomechanical environment systematically constitutes an experimental exercise model that allows the specific function of the different muscles and joint-specific consequences for joint forces to be studied separately during running.

Previous studies have estimated joint compression forces between 8 to 14 times $\mathrm{BW}$ at the ankle and 7 to 11 times $\mathrm{BW}$ at the knee during running. ${ }^{7,8,10}$ The present ground reaction force was largely reduced in parallel with the increasing BW support as predicted in the hypothesis. These decreases contribute to a reduction of the lower extremity joint forces during running, although the internal sources, ie, muscle forces, are the major determinant of joint forces. ${ }^{10}$ Based on the present results on ground reaction force and EMG, peak joint force reduction was estimated, assuming near linear association between EMG, expressed as \% $\mathrm{EMG}_{\max }$, and muscle force for the specific muscle. The EMG/force relationship during dynamic contractions has been debated in the literature and should be used with caution as it depends on muscle length changes and contraction type. ${ }^{11,12}$ However, gradually increasing weight support while running on the LBPP treadmill does not induce changes in contraction type, muscle length, or major changes in muscle shortening/lengthening velocities. Therefore, it seems reasonable to 
$3 \mathrm{~A}$

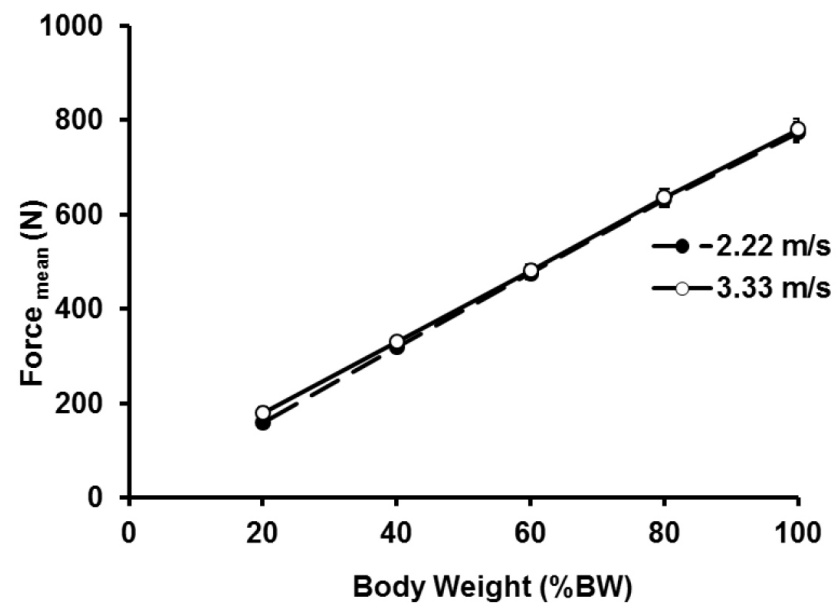

3B

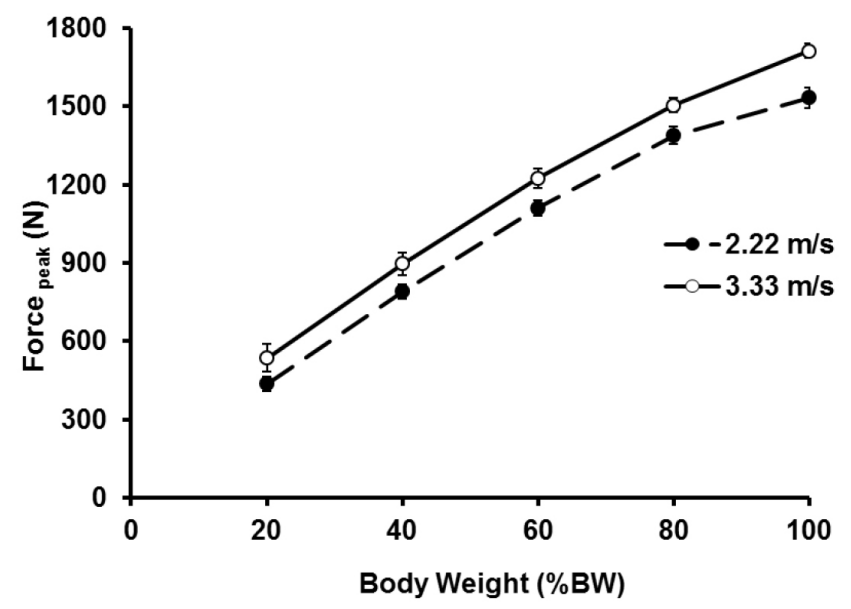

Figure 3 - Vertical ground reaction force as a function of body weight support $(\mathrm{n}=8)$. (A) Mean ground reaction force $(4-6 \mathrm{~min})$. (B) Peak ground reaction force (4-6 $\mathrm{min})$. Mean \pm SEM.

assume that the EMG/force relationship remains largely independent on weight support, which allows us to estimate relative changes in joint force using $100 \% \mathrm{BW}$ as a reference.

Our EMG data indicated that the relative effect on the mechanical joint load of supporting BW in the LBPP chamber during running differed between the knee joint and the ankle joint. Thus, we estimated knee joint compression forces to be reduced largely in parallel with the body weight, as the $\mathrm{GRF}_{\text {peak }}$ was reduced to $28 \%$ (at $2.22 \mathrm{~m} / \mathrm{s}$ ) and $31 \%$ (at $3.33 \mathrm{~m} / \mathrm{s}$ ) of the initial values at $100 \%$ $\mathrm{BW}$, and the $\mathrm{EMG}_{\text {peak }}$ of the VL and VM muscles was reduced to $22 \%$ and $28 \%$ at $80 \%$ weight support. In contrast, estimated relative ankle joint forces were less affected by weight support. Our model estimated a knee joint force of approximately $26 \%$ and an ankle joint force of approximately $47 \%$ at $80 \%$ weight support. Thus,

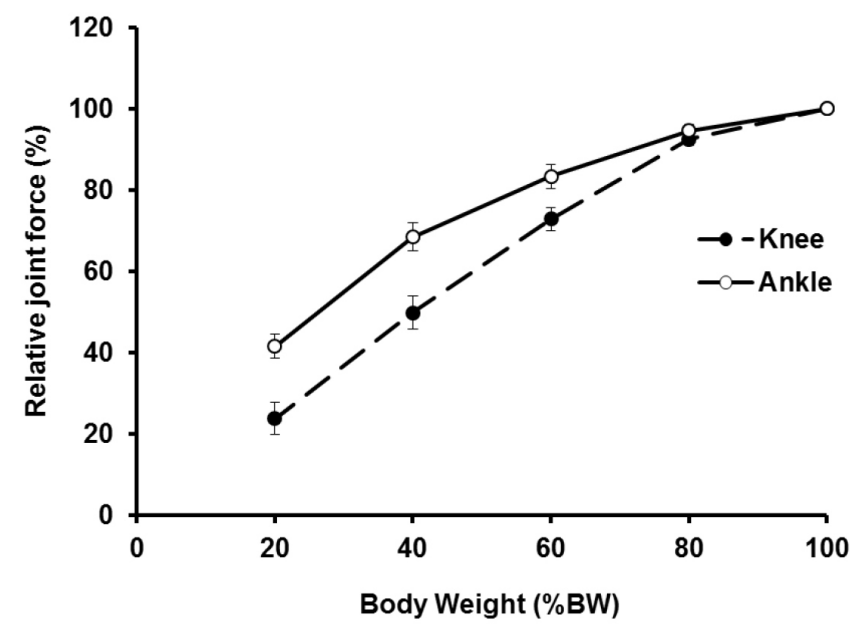

$4 B$

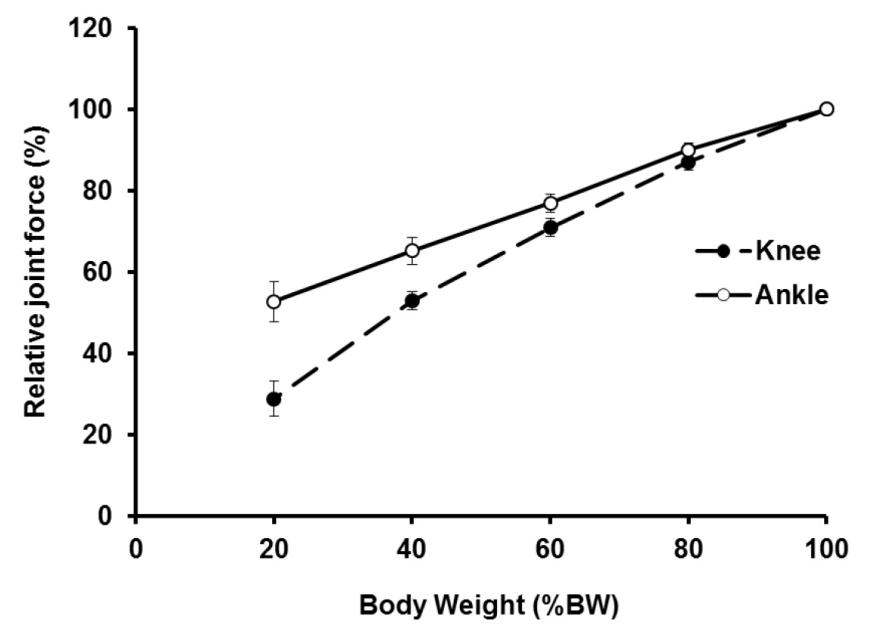

Figure 4 - Estimated relative joint forces (knee and ankle) as a function of body weight support $(\mathrm{n}=8)$. (A) $2.22 \mathrm{~m} / \mathrm{s}$. (B) $3.33 \mathrm{~m} / \mathrm{s}$. Mean \pm SEM. $(n=8)$

the study emphasizes that a change of the biomechanical environment through increasing weight support in the LBPP chamber has different effects on the knee and the ankle joint force due to the muscle-specific effect of BW support. These results should be taken into account in rehabilitation.

Noncontact anterior cruciate ligament injuries are most likely to happen during deceleration and acceleration of the body against gravity. The literature consistently shows that the anterior cruciate ligament is the major restraint against anterior shear forces applied to the tibia relative to the femur. ${ }^{13,14}$ Quadriceps muscle forces provide anterior shear forces on the tibia while cocontraction of the hamstrings is protective to the anterior cruciate ligament, as they provide a posterior shear force on the tibia. ${ }^{15,16}$ The potential role of the gastrocnemius muscle force for anterior cruciate ligament 
strain is less clear. ${ }^{14} \mathrm{~A}$ change in the relative contribution of the knee muscle forces between the quadriceps, hamstrings, and gastrocnemius muscles is therefore expected to influence the net shear forces in the knee. The present results showed that the activity of the knee extensors is reduced significantly, while the BF muscle activity was maintained when unweighting the body. Thus, running with weight support changes knee muscle function toward facilitation of antagonist (hamstring) activity relative to agonist (quadriceps) activity. It is therefore expected that the anterior cruciate ligament tensile force due to the muscle contraction decreases significantly when running with BW support, which may protect the anterior cruciate ligament against injury.

The current study had inherent strengths and limitations. Estimates of joint loads are often based on data from a few subjects and single step cycles, and model limitations and assumptions regarding force distribution between muscles introduce nontrivial errors. $7,8,10,17,18$ The present experimental approach used to estimate relative joint force included data from internal (muscle activity) as well as external (ground reaction force) sources recorded across 3 minutes (378-504 steps) for each trial, which is a strength of the study. A limitation of this study is the assumption regarding the EMG-force relationship, which is complex during dynamic contractions as it depends on muscle length and contraction velocity and type. ${ }^{11,12}$ Another limitation is that only knee extensor and plantar flexor muscles were included in the model. The present effect of unweighting on joint forces is therefore discussed relative to the $100 \%$ BW condition only. The inverse dynamic method would be beneficial for determination of absolute joint forces. However, this is not possible with the LBPP device. Changing muscle coordination pattern can affect joint loads significantly even when the movement pattern is largely maintained. In the current study no indication of change in muscle coordination with increasing BW support was found in the medial-lateral direction (VL vs. VM) or when increasing running speed support. Hip muscles were not included in the current study, and it is therefore not known if the subjects changed the relative activation between knee extensor muscles and hip muscles with increasing BW support. This is a limitation of the study. Finally, joint angles were not measured.

For comparison with our results, we found 2 studies on the effect of body weight support on peak tibiofemoral forces, as provided by LBPP (Patil et al, ${ }^{3} \mathrm{n}=4$; Macias et al, ${ }^{19} \mathrm{n}=1$ ). The subjects were implanted with instrumented knee prostheses and net tibiofemoral contact forces were measured. Patil et $\mathrm{al}^{3}$ found that the peak tibial force at $25 \% \mathrm{BW}$ relative to peak tibial force at $100 \% \mathrm{BW}$ was $1.9 \mathrm{BW} / 5.1 \mathrm{BW}$, corresponding to $37 \%$ at $25 \%$ BW. Macias et $\mathrm{al}^{19}$ found an uneven load distribution between the instrumented leg and the healthy leg at high relative BWs and "high" velocity, tending toward more load on the healthy leg. This means that, in healthy subjects, with an even load distribution between left and right leg, we may expect values lower than $37 \%$, as found by Patil et al. ${ }^{3}$ Macias et $\mathrm{al}^{19}$ found values of approximately $30 \%$ at $20 \%$ BW (based on readings from their Figure 6). Again, this value could be a bit overestimated due to the uneven weight distribution between the implanted knee and the healthy knee. ${ }^{19}$ For comparison, we estimated knee joint force at $20 \% \mathrm{BW}$ to be $24 \%(2.22 \mathrm{~m} / \mathrm{s})$ and $29 \%(3.3 \mathrm{~m} / \mathrm{s})$ of the initial value at $100 \% \mathrm{BW}$ for healthy subjects. Thus, our results regarding estimated joint forces mainly agree with previous results obtained with direct measurements of joint force in instrumented knee prostheses.

A number of training and rehabilitation modalities, eg, harness systems and swimming pools, are currently being used to allow movements and exercise for patients with a need for weight support. However, the available systems are not optimal since harness systems may not be used over prolonged periods of time due to discomfort and impeded circulation. Movements in deep water may help to maintain the aerobic fitness, but the neuromuscular training and the movement pattern are very different from normal movements, as the forces applied to the body in water differ significantly from the forces during overground movements (eg, $\left.{ }^{20-22}\right)$. Ambulation in a LBPP chamber may be beneficial not only for early mobilization after injury and surgery, ${ }^{23}$ but also as a motor evaluation and learning tool for neuromuscular patients, as motor control can be challenged systematically.

In summary, running with BW support in a LBPP treadmill chamber allows the biomechanical environment and motor demand to be manipulated systematically. Participants adapted activation levels of the individual leg muscles to the new biomechanical conditions and maintained near normal movement patterns, while the estimated joint forces were reduced significantly. Estimated joint force reduction was more pronounced for the knee than for the ankle joint.

\section{Acknowledgments}

Financial support for this study was provided by a Team-DK research grant. We thank Annesofie Thorup Olesen and Martin Rose for technical support.

\section{References}

1. Rose MH, Lokkegaard A, Sonne-Holm S, Jensen BR. Improved clinical status, quality of life, and walking capacity in Parkinson's disease after body weight-supported high-intensity locomotor training. Arch Phys Med Rehabil. 2013;94:687-692. PubMed doi:10.1016/j. apmr.2012.11.025

2. Berthelsen MP, Husu E, Christensen SB, Prahm KP, Vissing J, Jensen BR. Anti-gravity training improves walking capacity and postural balance in patients with muscular dystrophy. Neuromuscul Disord. 2014;24:492-498. PubMed doi:10.1016/j.nmd.2014.03.001

3. Patil S, Steklov N, Bugbee WD, Goldberg T, Colwell CW, Jr, D'Lima DD. Anti-gravity treadmills are effective in reducing knee forces. $J$ Orthop Res. 2013;31:672-679. PubMed doi:10.1002/jor.22272

4. Grabowski AM, Kram R. Effects of velocity and weight support on ground reaction forces and metabolic power during running. $J$ Appl Biomech. 2008;24(3):288-297. PubMed

5. Raffalt PC, Hovgaard-Hansen L, Jensen BR. Running on a lowerbody positive pressure treadmill: VO2max, respiratory response, and vertical ground reaction force. Res Q Exerc Sport. 2013;84:213-222. PubMed doi:10.1080/02701367.2013.784721

6. Cutuk A, Groppo ER, Quigley EJ, White KW, Pedowitz RA, Hargens AR. Ambulation in simulated fractional gravity using lower body positive pressure: cardiovascular safety and gait analyses. J Appl Physiol. 2006;101(3):771-777. PubMed doi:10.1152/japplphysiol.00644.2005

7. Burdett RG. Forces predicted at the ankle during running. Med Sci Sports Exerc. 1982;14(4):308-316. PubMed doi:10.1249/00005768198204000-00010

8. Scott SH, Winter DA. Internal forces at chronic running injury sites. Med Sci Sports Exerc. 1990;22(3):357-369. PubMed doi:10.1249/00005768-199006000-00013

9. Edwards WB, Gillette JC, Thomas JM, Derrick TR. Internal femoral forces and moments during running: implications for stress fracture development. Clin Biomech (Bristol, Avon). 2008;23(10):1269-1278. PubMed doi:10.1016/j.clinbiomech.2008.06.011 
10. Sasimontonkul S, Bay BK, Pavol MJ. Bone contact forces on the distal tibia during the stance phase of running. J Biomech. 2007;40(15):35033509. PubMed doi:10.1016/j.jbiomech.2007.05.024

11. Olney SJ, Winter DA. Predictions of knee and ankle moments of force in walking from EMG and kinematic data. J Biomech. 1985;18(1):920. PubMed doi:10.1016/0021-9290(85)90041-7

12. Heintz S, Gutierrez-Farewik EM. Static optimization of muscle forces during gait in comparison to EMG-to-force processing approach. Gait Posture. 2007;26(2):279-288. PubMed doi:10.1016/j.gaitpost.2006.09.074

13. Shelburne KB, Torry MR, Pandy MG. Muscle, ligament, and joint-contact forces at the knee during walking. Med Sci Sports Exerc. 2005;37(11):1948-1956. PubMed doi:10.1249/01. mss.0000180404.86078.ff

14. Shimokochi Y, Shultz SJ. Mechanisms of noncontact anterior cruciate ligament injury. J Athl Train. 2008;43(4):396-408. PubMed doi:10.4085/1062-6050-43.4.396

15. Li G, Rudy TW, Sakane M, Kanamori A, Ma CB, Woo SL. The importance of quadriceps and hamstring muscle loading on knee kinematics and in-situ forces in the ACL. J Biomech. 1999;32(4):395-400. PubMed doi:10.1016/S0021-9290(98)00181-X

16. Withrow TJ, Huston LJ, Wojtys EM, Ashton-Miller JA. Effect of varying hamstring tension on anterior cruciate ligament strain during in vitro impulsive knee flexion and compression loading. J Bone Joint Surg Am. 2008;90(4):815-823. PubMed doi:10.2106/JBJS.F.01352
17. Glitsch U, Baumann W. The three-dimensional determination of internal loads in the lower extremity. J Biomech. 1997;30(1112):1123-1131. PubMed doi:10.1016/S0021-9290(97)00089-4

18. Meyer AJ, D'Lima DD, Besier TF, Lloyd DG, Colwell CW, Jr, Fregly BJ. Are external knee load and EMG measures accurate indicators of internal knee contact forces during gait? J Orthop Res. 2013;31:921929. PubMed doi:10.1002/jor.22304

19. Macias BR, D'Lima DD, Cutuk A, et al. Leg intramuscular pressures and in vivo knee forces during lower body positive and negative pressure treadmill exercise. J Appl Physiol (1985). 2012;113(1):31-38. PubMed

20. Berman A, Studenski S. Musculoskeletal rehabilitation. Clin Geriatr Med. 1998;14(3):641-659. PubMed

21. Ruckstuhl H, Kho J, Weed M, Wilkinson MW, Hargens AR. Comparing two devices of suspended treadmill walking by varying body unloading and Froude number. Gait Posture. 2009;30(4):446-451. PubMed doi:10.1016/j.gaitpost.2009.07.001

22. Gill SD, McBurney H, Schulz DL. Land-based versus pool-based exercise for people awaiting joint replacement surgery of the hip or knee: results of a randomized controlled trial. Arch Phys Med Rehabil. 2009;90(3):388-394. PubMed doi:10.1016/j.apmr.2008.09.561

23. Eastlack RK, Hargens AR, Groppo ER, Steinbach GC, White KK, Pedowitz RA. Lower body positive-pressure exercise after knee surgery. Clin Orthop Relat Res. 2005; (431):213-219. PubMed doi:10.1097/01.blo.0000150459.92012.f7 